\title{
ATIVIDADES DE INVESTIGAÇÃO NO ENSINO DE ASTRONOMIA: SEQUÊNCIA DIDÁTICA SOBRE OS MOVIMENTOS E INCLINAÇÃO DO EIXO DA TERRA NOS ANOS INICIAIS DO ENSINO FUNDAMENTAL
}

\author{
RESEARCH ACTIVITIES IN TEACHING ASTRONOMY: DIDATIC SEQUENCE ON MOVEMENTS AND \\ INCLINATION OF THE EARTH AXIS IN THE ELEMENTARY SCHOOL
}

\section{ACTIVIDADES DE INVESTIGACIÓN EN LA ENSEÑANZA DE ASTRONOMIÍA: SECUENCIA DE ENSEÑANZA SOBRE MOVIMIENTOS Y INCLINACIÓN DEL EJE DE LA TIERRA EN LA EDUCACIÓN PRIMARIA}

\author{
ANA CAROLINE GONÇALVES GOMES DOS SANTOS ${ }^{1}$ \\ VERA DE MATTOS MACHADO²
}

\section{RESUMO}

A astronomia é fundamental para a compreensão de fenômenos do cotidiano. No entanto, existem limitações no processo de ensino e aprendizagem dessa Ciência, demandando o uso de abordagens didáticas voltadas para a alfabetização científica e para processos de ensino e aprendizagem mais significativos. Nessa perspectiva, desenvolvemos uma Sequência Didática com Atividades Investigativas (SDAI), com fundamentos no Ensino por Investigação e na Teoria Histórico-Cultural, para identificar indícios de aprendizagem de conceitos de astronomia e facilitar a construção de conhecimentos de alunos de $4^{0}$ ano do Ensino Fundamental. A partir da análise das falas dos estudantes, verificamos 0 emprego de concepções sobre os movimentos, formato e inclinação da Terra no processo de resolução de um problema, apesar da complexidade dos conceitos em construção. De modo geral, consideramos que a SDAl iniciou a elaboração de alguns conceitos de astronomia e de habilidades da prática científica, construindo bases para aprendizagens futuras.

Palavras-chave: Ensino de astronomia. Ensino por Investigação. Sequência Didática. Teoria Histórico-Cultural.

\section{ABSTRACT}

Astronomy is fundamental for understanding everyday's phenomena. However, there are limitations in the teaching and learning process of this Science, requiring the use of didactic approaches aimed at scientific literacy and more significant teaching and learning processes. In this perspective, we developed a Didactic Sequence with Investigative Activities (DSIA), based on Investigative Teaching and Historical-Cultural Theory, to identify signs of learning astronomy concepts and facilitate the construction of knowledge of elementary school students. From the analysis of the students' speeches, we verified the use of conceptions about the Earth's movements, shape and inclination in the process of solving a problem, despite the complexity of the concepts under construction. In general, we consider that DSIA started to elaborate some concepts of astronomy and scientific practice skills, building bases for future learning.

Keywords: Astronomy teaching. Investigative Teaching. Didactic Sequence. Cultural-Historical Theory.

\footnotetext{
1 Mestre em Ensino de Ciências pela Universidade Federal de Mato Grosso do Sul (UFMS). Doutoranda em Ensino de Ciências pela Universidade Federal de Mato Grosso do Sul, Campo Grande, Mato Grosso do Sul. E-mail: ana.goncalves@ufms.br. ORCID: https://orcid.org/00000003-0478-7114.

2 Doutora em Educação pela Universidade Federal de Mato Grosso do Sul (UFMS). Professora da Universidade Federal de Mato Grosso do Sul, Campo Grande, Mato Grosso do Sul. E-mail: veramattosmachad01@gmail.com. ORCID: https://orcid.org/0000-0002-5595-400X.
} 


\section{RESUMEN}

La astronomía es fundamental para comprender los fenómenos cotidianos. Sin embargo, existen limitaciones en el proceso de enseñanza y aprendizaje de esta Ciencia, requiriendo el uso de enfoques didácticos orientados a la alfabetización científica y procesos de enseñanza y aprendizaje más significativos. En esta perspectiva, desarrollamos una Secuencia Didáctica con Actividades Investigativas (SDAl), basada en la Enseñanza Basada en Investigación y la Teoría Histórico-Cultural, para identificar signos de aprendizaje de conceptos astronómicos y facilitar la construcción de conocimientos de los alumnos de la educación primaria. A partir del análisis de los discursos de los estudiantes, comprobamos el uso de concepciones sobre los movimientos, forma e inclinación de la Tierra en el proceso de resolución de un problema, a pesar de la complejidad de los conceptos en construcción. En general, consideramos que SDAl comenzó a elaborar algunos conceptos de astronomía y habilidades de práctica científica, construyendo bases para futuros aprendizajes.

Palabras-clave: Enseñanza de astronomía. Enseñanza Basada en Investigación. Secuencia de Enseñanza. Teoría Histórico-Cultural.

\section{INTRODUÇÃO}

A alfabetização científica se configura como um dos principais objetivos do ensino de Ciências na atualidade e almeja uma formação cidadã que vá além da tradicional transmissão de conhecimentos científicos, e favoreça o domínio e uso de conhecimentos da Ciência para uma tomada fundamentada de decisões em situações do cotidiano (CACHAPUZ et al., 2005; SASSERON; CARVALH0, 2011).

Nessa perspectiva, diferentes pesquisadores, entre eles Gil-Pérez e Vilches (2001), Sasseron e Carvalho (2008, 2011), defendem que o ensino de Ciências precisa ser planejado como uma atividade próxima a uma investigação científica, voltada para a resolução de problemas, e contemplando conhecimentos da Ciência e sobre a Ciência, para que se construa, gradativamente, a alfabetização científica.

0 Ensino por Investigação surge como uma alternativa para o desenvolvimento da alfabetização científica em sala de aula (SASSERON, 2015, 2018) e para promover aprendizagens com uma postura mais ativa dos alunos. Carvalho (2018, p. 766, grifo nosso) define o Ensino por Investigação como o ensino de conteúdos programáticos em que o professor promove condições para os estudantes: "pensarem, levando em conta a estrutura do conhecimento; falarem, evidenciando seus argumentos e conhecimentos construídos; lerem, entendendo criticamente o conteúdo lido; escreverem, mostrando autoria e clareza nas ideias expostas.".

Considerando as potencialidades do Ensino por Investigação, o uso dessa abordagem se torna pertinente para facilitar a aprendizagem de conceitos complexos, como os de astronomia. A astronomia é uma Ciência intrínseca ao dia a dia e de fundamental importância para o reconhecimento de vários fenômenos da natureza. Por despertar fascínio e curiosidade, os conceitos de astronomia podem ser propícios para o desenvolvimento de atividades que permitam problematizações, expressão de ideias, construção de hipóteses, argumentação, manipulação de materiais e informações, divulgação de dados, entre outras.

Entendemos que tais atividades são importantes para o desenvolvimento gradativo da alfabetização científica ao longo da Educação Básica, e podem minimizar as dificuldades existentes no processo de ensino e aprendizagem de astronomia, manifestadas, principalmente, pela persistência de concepções alternativas (LANGHI; NARDI, 2007; LANGHI, 2009, 2011). 
Também é importante que os próprios conceitos de astronomia sejam desenvolvidos de forma gradativa, devido à complexidade e ao alto grau de abstração. Segundo Vigotski (2009), a apropriação de conceitos científicos é um processo complexo que envolve o uso de muitas funções psicológicas por parte dos alunos. Além disso, de acordo com a Teoria Histórico-Cultural, a elaboração de um conceito muitas vezes não coincide com o tempo determinado pelo currículo escolar, pois quando uma nova palavra é aprendida o processo de sua construção apenas se iniciou, ampliando-se à medida que novos conceitos são incorporados ao sistema de elaboração conceitual (VIGOTSKI, 2009).

Nesse âmbito, devemos nos atentar às diferentes etapas de construção de conceitos, sobretudo os científicos, pois todo o conceito, seja qual for o nível de desenvolvimento, é, em termos psicológicos, um ato de generalização e o significado das palavras se modifica ao longo do processo de desenvolvimento de um indivíduo (VIGOTSKI, 2009). A generalização, entendida como a construção do significado de um conceito, ainda depende da maturação de estruturas neurais e da qualidade das situações sociais vivenciadas. Assim, é importante que as propostas didáticas estejam de acordo com 0 nível de desenvolvimento dos alunos, para que não sejam oferecidas tarefas pouco desafiadoras ou difíceis demais.

Com base nesses fundamentos, apresentamos, neste artigo, um recorte de uma pesquisa de doutorado no qual elaboramos uma Sequência Didática com Atividades Investigativas (SDAI) fundamentada no Ensino por Investigação e na Teoria Histórico-Cultural. Na SDAl, desenvolvemos atividades sobre os movimentos e inclinação do eixo da Terra, a partir de um problema sobre o Sol da meia-noite, com alunos de $4^{0}$ ano do Ensino Fundamental de uma escola pública municipal de Campo Grande, Mato Grosso do Sul. Com a abordagem, tivemos o objetivo de identificar indícios de aprendizagem de conceitos de astronomia e facilitar a construção de alguns conhecimentos dessa Ciência pelos alunos.

Diante do exposto, buscamos, neste recorte, respostas para a seguinte questão: quais indícios de aprendizagem são apresentados por alunos dos anos iniciais em uma SDAl sobre os movimentos e inclinação do eixo da Terra?

\section{A ASTRONOMIA NA EDUCAÇÃO BÁSICA: CONHECENDO LIMITAÇÕES E APONTANDO 0 ENSINO POR INVESTIGAÇÃO COMO POSSIBILIDADE}

A astronomia é uma das ciências mais antigas elaboradas pelo ser humano. 0 processo de construção de conhecimentos astronômicos possibilitou a compreensão de muitos fenômenos do nosso planeta e do Universo. Conforme Bartelmebs e Moraes (2012, p. 342), "sem os conhecimentos da astronomia não seria possível pensarmos no universo a não ser baseados em mitos e ideias pouco desenvolvidas baseadas apenas naquilo que podemos ver através de nossas sensações.".

A sucessão dos dias e das noites, a divisão do tempo em horas, minutos e segundos, 0 calendário com 365 dias e as estações do ano são alguns exemplos de conhecimentos ligados à astronomia (LANGHI, 2009). Apesar de ser uma Ciência intrínseca ao nosso dia a dia e despertar fascínio, ainda há persistência de concepções equivocadas sobre conceitos de astronomia entre alunos e professores da Educação Básica.

Sobre isso, Paschini Neto e Tommasiello (2017), fundamentados em Langui (2004), ressaltam que as crianças apresentam um entendimento intuitivo dos movimentos e fenômenos astronômicos, baseado em suas experiências diárias, crenças e contatos com outras pessoas. Outro ponto levantado por Paschini Neto e Tommasiello é a contradição entre 0 que 0 aluno vê em seu dia a dia, 
enquanto um observador na Terra, e o que o professor ensina em sala de aula, que normalmente está relacionado à visão de um observador no espaço. Para os autores, "se os professores não souberem trabalhar essa contradição entre o que é observado e o que é aceito pela ciência hoje, eles, sem intenção, podem contribuir para a geração de concepções alternativas nos estudantes." (PASCHINI NETO; TOMMASIELLO, 2017, p. 115).

Entende-se as concepções alternativas como ideias de senso comum (LANGHI, 2011), que se distanciam de conhecimentos científicos. Entre as concepções alternativas mais habituais em astronomia, Langhi e Nardi (2007) destacam: a ideia de que a distância da Terra em relação ao Sol provoca as diferentes estações do ano; a visão geocêntrica do Universo; a concepção das fases da Lua como eclipses lunares semanais; o pensamento de que existem estrelas entre os planetas do Sistema Solar; o desconhecimento do movimento aparente das estrelas no céu; a percepção de que a Lua está presente apenas à noite; e a visão de que a existência da força de gravidade está relacionada com a presença do ar, pois só existe gravidade onde há atmosfera.

Quanto aos professores, Langhi (2011) enfatiza as dificuldades no ensino de astronomia, relatando que, em alguns casos, os próprios docentes ensinam concepções alternativas. 0 autor ressalta que muitas vezes os professores explicam os fenômenos astronômicos baseados em "representações idealizadas e simplificadas, distantes do observável do cotidiano" (LANGHI, 2011, p. 375), prejudicando o processo de elaboração conceitual dos alunos.

Tais dificuldades, segundo Langhi (2011), estão relacionadas a limitações na formação inicial, que não dá subsídios suficientes para ministrar os conteúdos de astronomia. Essas limitações levam os professores a uma série de situações de despreparo, como insegurança ao trabalhar com o tema, poucas contextualizações do conteúdo, baixo discernimento de bibliografias sobre astronomia, dificuldades para identificar erros conceituais (LANGHI; NARDI, 2007; LANGHI, 2011), entre outras.

As dificuldades em ensinar astronomia são apontadas por Langhi (2011), e outros autores, como uma das principais causas para a persistência das concepções alternativas. Conforme salienta o autor,

[...] o docente não capacitado e não habilitado para o ensino da Astronomia durante sua formação inicial promove o seu trabalho educacional com as crianças sobre um suporte instável, cuja base pode vir das mais variadas fontes de consulta, desde a mídia até livros didáticos com erros conceituais, proporcionando uma propagação de concepções alternativas. Essas considerações apontam para um ciclo de propagação de concepções alternativas incorporadas nos saberes docentes de conteúdo disciplinar sobre tópicos de Astronomia que perpassam a trajetória formativa docente [...]. (LANGHI, 2011, p. 386).

0 conhecimento das limitações no processo de ensino e aprendizagem da astronomia é importante para promover esclarecimentos e fomentar alternativas que tornem esse processo menos laborioso e mais significativo. Sabe-se o quanto os conhecimentos de astronomia são importantes para a compressão dos fenômenos que regem o Universo, e, por ser uma Ciência que gera tanta curiosidade e admiração, é necessário que não se dê tanta ênfase ao ensino de definições e conceitos prontos, mas sim que se coloque em prática abordagens que incentivem a investigação, o protagonismo na construção do próprio conhecimento, oportunidades de expressão de ideias e aproximações com práticas da cultura científica. 
Nesse cenário, a abordagem didática do Ensino por Investigação pode ser uma alternativa, pois, além de proporcionar a construção de habilidades cognitivas, como observação, registro, análise de dados, comparação, percepção de evidências, raciocínio e argumentação (ZOMPERO; GONÇALVES; LABURÚ, 2017), incentiva a construção de conhecimentos científicos por meio de um processo de investigação que se aproxima de práticas da comunidade científica.

Conforme Sasseron (2015), o Ensino por Investigação se caracteriza como uma abordagem didática desenvolvida pelo professor e que pode estar relacionada a qualquer conteúdo do ensino. Nessa abordagem, o professor coloca em prática habilidades que possibilitam a construção de conhecimentos por meio da resolução de problemas. Além disso, de acordo com Carvalho (2018), no Ensino por Investigação não se avalia apenas a aprendizagem do conteúdo, mas também se os estudantes conseguem falar, argumentar, ler e escrever sobre o conteúdo ministrado.

Essas características também tornam 0 Ensino por Investigação uma abordagem adequada para 0 desenvolvimento da alfabetização científica. Para Sasseron e Carvalho (2008, p. 335), a alfabetização científica compreende um conjunto de habilidades, como a "compreensão básica de termos, conhecimentos e conceitos científicos fundamentais"; a "compreensão da natureza da ciência e dos fatores éticos e políticos que circundam sua prática"; e o "entendimento das relações existentes entre ciência, tecnologia, sociedade e meio-ambiente". As autoras também salientam a necessidade de iniciar o processo de alfabetização científica já nos primeiros anos de escolarização, a partir de atividades voltadas para a resolução de problemas.

Ademais, devemos salientar a complexidade dos conceitos inerentes à astronomia, que têm bases complexas e, em muitos casos, não são diretamente observáveis, tornando 0 ensino dos conceitos abstrato. 0 processo de construção de conceitos científicos em si já é bastante complexo, não ocorre de forma imediata e pode não acompanhar a programação estabelecida no planejamento escolar (VIGOTSKI, 2009). Sendo assim, é importante que o ensino de conceitos de astronomia ocorra de forma gradual e articulada ao cotidiano dos alunos.

Diante do exposto, a manipulação de modelos didáticos pelos alunos, no contexto do Ensino por Investigação, é interessante para desenvolver temas de astronomia a partir do que se vê (plano topocêntrico) para depois transpor ao que não se vê (plano heliocêntrico), permitindo uma melhor compreensão dos fenômenos astronômicos, a construção de conceitos e o desenvolvimento gradual da alfabetização científica.

Vale ressaltar que a modelagem didática é uma estratégia pertinente para facilitar a aprendizagem de conteúdos complexos e de difícil compreensão (SETúVAL; BEJARANO, 2009), como os de astronomia. Conforme Vinholi Júnior e Princival (2014), vários estudos apontam as contribuições do uso de modelos didáticos na promoção de aprendizagens que sobrepujam a mera memorização de conceitos, e que favorecem o desenvolvimento de habilidades e conhecimentos críticos aplicáveis em situações do dia a dia. Diante dessas vantagens, destacamos a relevância do uso de modelos didáticos articulados ao Ensino por Investigação, conforme mencionado anteriormente.

Assim, desenvolvemos uma Sequência Didática com Atividades Investigativas (SDAl), apresentada a seguir, para promover aprendizagens sobre os movimentos e a inclinação do eixo da Terra a partir de um problema sobre o fenômeno do Sol da meia-noite. 


\section{OS PROCEDIMENTOS DA PESQUISA}

A SDAI foi desenvolvida no laboratório de Ciências, durante 2 horas/aula, com alunos de $4^{0}$ ano do Ensino Fundamental de uma escola pública municipal localizada em Campo Grande, Mato Grosso do Sul.

De acordo com Zabala (1998, p. 18), as sequências didáticas são um "conjunto de atividades ordenadas, estruturadas e articuladas para a realização de certos objetivos educacionais, que têm um princípio e um fim conhecidos tanto pelos professores como pelos alunos". As sequências didáticas também são instrumentos que permitem incluir as três fases de toda intervenção pedagógica: o planejamento, a aplicação e a avaliação. Desse modo, elas ajudam a indicar a função que cada atividade tem na construção do conhecimento, bem como avaliar os resultados de cada uma delas no processo de ensino e aprendizagem.

A SDAl foi desenvolvida com o objetivo de mobilizar conhecimentos sobre os movimentos da Terra e promover o reconhecimento da inclinação do eixo da Terra como fator de diferentes incidências da luz solar e como causa da ocorrência do Sol da meia-noite nos polos. Ela foi organizada em cinco atividades, fundamentadas na perspectiva histórico-cultural do desenvolvimento humano e em estudos relativos ao Ensino por Investigação, como os de Zômpero e Laburú (2011), Carvalho (2013) e Trivelato e Tonidandel (2015).

\section{Descrição das atividades da Sequência Didática com Atividades Investigativas}

\section{Atividade 1: Investigação das concepções cotidianas sobre o conteúdo}

Nesta atividade, realizamos uma investigação das concepções cotidianas dos alunos a partir de uma conversa em que eles foram estimulados a falar o que sabiam sobre o tema da SDAI. Essa investigação inicial é importante, pois, conforme Vigotski (2009), os conceitos cotidianos, aqueles adquiridos em experiências práticas, fazem parte do processo de construção dos conceitos científicos. Além disso, essa investigação permite uma melhor adequação dos novos conhecimentos ao nível de desenvolvimento dos alunos, ou às suas zonas de desenvolvimento proximal (ZDP) ${ }^{3}$, evitando-se, assim, que sejam oferecidas tarefas pouco desafiadoras ou difíceis demais.

\section{Atividade 2: Proposição de uma situação problema}

Após a investigação dos conhecimentos dos alunos, contextualizamos a situação problema da SDAl com a exibição de um vídeo do YouTube ${ }^{4}$ que mostrou a ocorrência do Sol da meia-noite no Ártico.

A proposição de um problema é uma das etapas mais importantes na abordagem didática do Ensino por Investigação, pois é a partir do problema que o professor medeia as atividades investigativas em sala de aula. Dentro da perspectiva histórico-cultural, a mediação do processo de aprendizagem por meio de um problema também é pertinente, já que a formação de conceitos é um processo produtivo e não reprodutivo, e os conceitos surgem e se formam durante operações voltadas para a solução de problemas (VIGOTSKI, 2009).

3 A distância entre o que a criança é capaz de fazer sozinha (nível de desenvolvimento real) e aquilo que ela faz em colaboração com parceiros mais capazes (nível de desenvolvimento potencial) é chamada de zona de desenvolvimento proximal (VIGOTSKI, 2007).

4 Vídeo "Sol da meia noite no Ártico". Disponível em: https://www.youtube.com/watch?v=mGb7Xq86cl0\&t=43s. Acesso em: 18 abr. 2019. 
Depois da contextualização, propomos a seguinte situação problema: Por que acontece o fenômeno do Sol da meia-noite nos polos da Terra?

\section{Atividade 3: Elaboração de hipóteses}

Depois da proposição da situação problema, incentivamos os estudantes a elaborarem hipóteses para responder à questão. Destaca-se que esse momento é importante, pois oferece novas oportunidades de expressão aos alunos, que podem "explicitar seus conhecimentos e modelos explicativos sobre 0 assunto em questão", conforme explicam Trivelato e Tonidandel (2015, p. 109).

\section{Atividade 4: Interpretação de novas informações e verificação das hipóteses}

Logo após a etapa de formulação de hipóteses, organizamos os estudantes em pequenos grupos para desenvolver a experiência. À cada grupo, distribuímos um metro quadrado de papel kraft com um desenho da órbita terrestre marcada em quatro pontos (A, B, C, D), representando os equinócios e os solstícios; uma lâmpada presa a um soquete, fixa ao centro do papel; e uma bola de isopor, sustentada por uma base feita com tampa de garrafa pet, massa de modelar e um clipe dobrado, que deixava a bolinha em um ângulo de aproximadamente $23^{\circ}$ em relação ao papel. Na parte superior da bolinha, fixamos um palito de dente para representar o eixo imaginário da Terra, além disso, a bolinha estava dividida em dois hemisférios e o polo Norte estava marcado com tinta azul.

Explicamos a função de cada material aos alunos e orientamos os grupos a começarem a investigação simulando o movimento de translação e observando a incidência de luz nos dois hemisférios, conforme o planeta Terra (bola de isopor) completava a sua órbita. Também chamamos à atenção para a constância da direção do eixo terrestre, dessa forma, todos os grupos apontaram o palito de dente para a mesma direção. Os alunos já haviam realizado uma experiência sobre o movimento de translação e as estações do ano, com os mesmos materiais, em aulas anteriores e, como os conceitos trabalhados na SDAl se relacionam à investigação sobre o Sol da meia-noite, consideramos pertinente retomá-la.

Após a simulação do movimento de translação, direcionamos a atenção dos alunos à região do polo Norte, pedindo para identificarem o ponto da órbita (A, B, C, D) em que seria o solstício de verão no hemisfério Norte. A partir daí, orientamos a simulação do movimento de rotação e a observação da incidência de luz solar no polo Norte.

0 momento de manipulação de materiais é importante para os alunos avaliarem e discutirem, coletivamente, a validade de suas hipóteses e construir justificativas para as suas respostas. Essa atividade também possibilita a interação entre os alunos e destes com a professora, processo importante para a elaboração de significados. Nessas interações, os alunos podem expressar, por meio da linguagem (oral e escrita), generalizações dos conceitos estudados.

\section{Atividade 5: Comunicação dos resultados do processo investigativo}

Após 0 desenvolvimento da experiência investigativa, retomamos a situação problema e solicitamos aos estudantes que registrassem em uma folha de papel a resposta encontrada. Também incentivamos a exposição oral dos resultados, momento que propicia debates e reelaboração de significados. A partir das falas dos alunos, sistematizamos os conhecimentos envolvidos na resolução da situação problema. 
0 momento de comunicar e justificar os resultados da investigação é importante para a ampliação do vocabulário (CARVALHO, 2013) e para o início do desenvolvimento da linguagem científica. Nessa atividade, assim como nas demais, salientamos, com base em Carvalho (2018), a importância de avaliar, também, o que os alunos sabem falar, argumentar, ler e escrever sobre o conteúdo desenvolvido.

\section{Construção dos dados para a análise}

Utilizamos registros escritos e filmagens das interações verbais estabelecidas durante as atividades da SDAI como a principal fonte de dados. Tais dados foram analisados de forma qualitativa, uma vez que essa abordagem permite "capturar os diferentes significados das experiências vividas no ambiente escolar de modo a auxiliar a compreensão das relações entre os indivíduos, seu contexto e suas ações" (ANDRÉ, 1983, p. 66).

Na interpretação dos dados, recorremos à Análise Microgenética fundamentada na Teoria Histórico-Cultural do desenvolvimento humano. Para Góes (2000, p. 9), a Análise Microgenética "requer a atenção a detalhes e o recorte de episódios interativos", o que resulta em um relato detalhado dos acontecimentos. Assim, essa análise se pauta na investigação de minúcias que dão indícios do processo de aprendizagem e desenvolvimento.

Como a Análise Microgenética gera uma grande quantidade de dados, recortamos as filmagens em episódios e destacamos aqueles que apresentavam possíveis indícios do processo de aprendizagem dos alunos durante os momentos de interação.

Os registros escritos foram organizados por meio de transcrições, que endossaram as interpretações dos episódios. Protegemos as identidades dos alunos identificando-os pelas letras do alfabeto romano/latino. A seguir, apresentamos as discussões e análises dos indícios de aprendizagem identificados.

\section{ANÁLISE DOS INDÍCIOS DE APRENDIZAGEM}

Com a intenção de investigar o que os alunos já sabiam sobre os conhecimentos envolvidos na SDAl, iniciamos a primeira atividade com uma conversa sobre os principais movimentos e inclinação do eixo da Terra, conforme 0 episódio a seguir.

Quadro 1 - Episódio 1 (Atividade 1 da SDAl).

\begin{tabular}{|c|l|}
\hline Turnos & \multicolumn{1}{c|}{ Diálogos estabelecidos } \\
\hline 1 & Professora: (...) crianças, a Terra realiza vários movimentos, como a gente já viu... e quais são os dois principais? \\
\hline 2 & Aluno 17: Rotação e translação. \\
\hline 3 & Professora: E qual a diferença entre eles mesmo? \\
\hline 4 & $\begin{array}{l}\text { Aluno 4: Gira em si (...) em volta do Sol (...). } \\
\text { Aluno 17: [em volta se si mesma, em volta do Sol (...). } \\
\text { Aluno 21: [rotação é no próprio eixo, translação em volta do Sol (...). }\end{array}$ \\
\hline 5 & $\begin{array}{l}\text { Professora: Muito bem, muito bem! Por conta da rotação temos os dias e as noites e por conta da translação temos as } \\
\text { estações do ano. E como acontecem as estações do ano? }\end{array}$ \\
\hline 6 & $\begin{array}{l}\text { Aluno 4: Depende do lugar onde ela ((Terra)) está. Se tiver aqui (apontando para o papel pardo em que estão marcadas as } \\
\text { posições de equinócios e solstícios), pega uma estação ou ali pega outra estação. }\end{array}$ \\
\hline
\end{tabular}




\begin{tabular}{|c|l|}
\hline 7 & Professora: E o que a luz do Sol tem a ver com as estações do ano? \\
\hline 8 & Aluno 4: (...) lugar do Sol (...). \\
\hline 9 & $\begin{array}{l}\text { Aluno 17: Lugar da Terra, depende, depende (...). } \\
\text { Aluno 11: [a Terra gira... }\end{array}$ \\
\hline 10 & Aluno 17: (...) às vezes ela fica mais perto, às vezes mais longe... \\
\hline 11 & Professora: Lembra o que conversamos sobre as estações do ano? \\
\hline 12 & Aluno 11: Ah, a Terra não era... reta... ela era meio inclinada. \\
\hline
\end{tabular}

Fonte: Construção dos autores.

A partir dos diálogos, verificamos que os alunos apresentavam algumas concepções sobre os principais movimentos terrestres e conseguiam, de certa forma, diferenciar um movimento do outro. Além disso, no que se refere às consequências dos movimentos da Terra, um aluno conseguiu relacionar as estações do ano à inclinação do planeta (Aluno 11: "Ah, a Terra não era... reta... ela era meio inclinada" - turno 12, Episódio 1). Consideramos que o estímulo da professora ("Lembra o que conversamos sobre as estações do ano?” - turno 11, Episódio 1) desencadeou a mobilização de conhecimentos já assimilados pelo aluno.

No entanto, alguns estudantes associaram as estações do ano ao movimento de rotação (Aluno 11: “... a Terra gira...” - turno 9, Episódio 1) e à distância da Terra em relação ao Sol (Aluno 17: "(...) às vezes ela fica mais perto, às vezes mais longe..." - turno 10 - Episódio 1). Outros ainda estabeleceram relações desordenadas e confusas em suas explicações (turno 9, Episódio 1).

É importante mencionar que os alunos já haviam estudado os fenômenos envolvidos nas estações no ano em aulas anteriores, contudo, conforme explica Vigotski (2009), acompanhar uma sequência de conteúdos não garante ao aluno a capacidade de estabelecer relações conscientes e imediatas com os conteúdos anteriormente apropriados, tendo em vista que o curso de desenvolvimento não coincide inteiramente com o curso de aprendizagem. Portanto, consideramos natural que os alunos ainda não conseguissem utilizar os conceitos de forma sistematizada.

Na segunda atividade, após a contextualização do tema por meio de conversas e um vídeo, propomos a situação problema e, em seguida, incentivamos a elaboração de hipóteses para o problema na terceira atividade, como se verifica no Episódio 2.

Quadro 2 - Episódio 2 (Atividade 3 da SDAl).

\begin{tabular}{|c|l|}
\hline Turnos & \multicolumn{1}{c|}{ Diálogos estabelecidos } \\
\hline 1 & Professora: (...) por que acontece o fenômeno do Sol da meia-noite nos polos da Terra? Alguém tem alguma ideia? \\
\hline 2 & $\begin{array}{l}\text { Aluno 17: Porque geralmente o Sol fica mais em cima, daí a parte de cima ((polo norte do planeta)) fica iluminada o dia } \\
\text { todo e a Lua fica na parte de baixo, que é noite no polo sul. }\end{array}$ \\
\hline 3 & $\begin{array}{l}\text { Aluno 11: Eu acho que... o planeta ele é meio inclinado, né? Daí eu acho que como o Sol tá em cima ele pega ali (polo norte) } \\
\text { e quando o sul tá embaixo não pega o Sol e quando as posições estão mudando, vai vindo o Sol para baixo e a Lua vai pra } \\
\text { cima e vai mudando. }\end{array}$ \\
\hline 4 & Professora: Será? Vamos testar isso..., mas alguém tem alguma hipótese? ((Nenhum aluno se manifesta)). \\
\hline
\end{tabular}

Fonte: Construção dos autores.

Em suas hipóteses, os alunos apresentaram dificuldades em articular suas ideias, externalizando algumas concepções alternativas, entre elas: a noção de "em cima" e "embaixo" no espaço e a de Terra plana, como evidencia-se na fala do turno 2 (Episódio 2). 
Na primeira atividade da SDAI, os alunos demonstraram conhecer algumas noções de astronomia, como movimentos de rotação e translação, esfericidade e inclinação do planeta Terra. No entanto, quando a situação didática mudou, manifestada por uma nova situação problema, os alunos não conseguiram empregar tais noções de forma sistematizada. Isso evidencia que as estruturas de generalização do pensamento das crianças ainda estão imaturas, mesmo que os significados das palavras coincidam com os da professora.

Considerando a importância e qualidade das situações sociais na generalização dos conceitos, é imprescindível que os alunos tenham oportunidades de expressar suas ideias, demonstrando aquilo que já sabem e o que são capazes de aprender sobre um tema. Nessa situação, a abordagem didática do Ensino por Investigação propicia esses momentos, porque demanda intensa participação do aluno durante a investigação de problemas.

Após o momento de formulação de hipóteses, iniciamos a etapa de experimentação (Atividade 4). Para que os alunos conseguissem relacionar com mais facilidade a experiência com conhecimentos já assimilados, solicitamos a simulação do movimento de translação para a observação da incidência de luz solar nos hemisférios do planeta Terra. Em seguida, retomamos o problema de investigação e orientamos os estudantes a identificar o ponto da órbita ( $A, B, C, D)$ em que seria 0 solstício de verão no hemisfério norte e, a partir daí, simular o movimento de rotação e observar a incidência de luz solar no polo norte. Esperávamos que os alunos reconhecessem a inclinação do eixo da Terra como um fator da ocorrência do Sol da meia-noite.

Reconhecendo a dinâmica do processo de elaboração de conceitos científicos, é importante considerar que a aprendizagem ocorre de maneira mais rápida quando 0 aluno consegue relacionar o novo objeto de conhecimento a algo que ele já conheça. Por este motivo decidimos iniciar a investigação a partir de uma experiência já conhecida pelos alunos. A seguir, apresentamos algumas discussões estabelecidas durante o desenvolvimento da Atividade 4.

Quadro 3 - Episódio 3 (Atividade 4 da SDAI).

\begin{tabular}{|c|l|}
\hline Turnos & \multicolumn{1}{c|}{ Diálogos estabelecidos } \\
\hline 1 & $\begin{array}{l}\text { (Professora se encaminha a um dos grupos). } \\
\text { Professora: Vocês conseguiram encontrar uma resposta? }\end{array}$ \\
\hline 2 & $\begin{array}{l}\text { Aluno 17: (...) eu acho que a Terra... foi que nem na última aula... a Terra é redonda e ela é inclinada e dependendo do } \\
\text { ângulo em que ela estiver, a luz pode pegar mais em um lugar do que no outro e isso pode fazer o Sol da meia-noite. (...) } \\
\text { sempre que fica em uma posição diferente ((o globo terrestre)) ... dependendo da inclinação da Terra, a luz vai iluminar } \\
\text { mais o hemisfério norte ou o sul... }\end{array}$ \\
\hline 3 & Professora: E como acontece o Sol da meia-noite? \\
\hline 4 & Aluno 2: Por causa que o Sol fica mais concentrado no hemisfério norte. \\
\hline 5 & Aluno 17: E lá embaixo, no hemisfério sul, o Sol fica mais fraquinho. \\
\hline 6 & Aluno 2: Muito mais fraco, por isso que lá fica 24 horas noite e em cima 24 horas dia. \\
\hline
\end{tabular}

Fonte: Construção dos autores.

Constata-se no Episódio 3 evoluções nas concepções dos alunos em relação à atividade de elaboração de hipóteses. Alguns estudantes conseguiram articular de maneira mais sistematizada os conhecimentos propiciados anteriormente à situação problema atual, que consistiu em investigar as 
causas do Sol da meia-noite. Em sua resposta ao problema, o Aluno 17 usou conhecimentos sobre a esfericidade e inclinação do planeta Terra, incidência de luz solar e movimentos terrestres, demonstrando evolução no processo de elaboração conceitual, à medida que usa conhecimentos científicos para fundamentar sua linguagem. Ao falar sobre a importância da linguagem científica na aprendizagem de astronomia, Bartelmebs e Moraes (2012, p. 346) sustentam que:

Toda vez que conseguimos construir uma nova compreensão a respeito de algum dos fenômenos do céu, ampliamos nossa visão de mundo e leitura da realidade. Somos capazes cada vez mais de entender palavras específicas dessa ciência e contextualizá-las nas situações do dia a dia. Isso porque cada vez que um sujeito aprende algo novo, ele modifica sua estrutura interna de compreensão e leitura da realidade. Ao mesmo tempo, torna-se capaz de ver outros observáveis dos objetos que antes não tinha condições de compreender.

Entretanto, os alunos não estavam no mesmo nível de aprendizagem e desenvolvimento e alguns ainda apresentavam dificuldades em aplicar os conhecimentos propiciados pela professora à resolução do problema sobre o Sol da meia-noite, conforme se verifica no Episódio 4.

Quadro 4 - Episódio 4 (Atividade 4 da SDAI).

\begin{tabular}{|c|l|}
\hline Turnos & \multicolumn{1}{c|}{ Diálogos estabelecidos } \\
\hline 1 & Professora: Vocês já descobriram por que acontece o Sol da meia-noite? \\
\hline 2 & $\begin{array}{l}\text { Aluno 27: Porque a Terra tá virada para cá... (apontando para o lado não iluminado do globo) e esse lado não vai conseguir } \\
\text { pegar Sol. O Sol, a luz, tá chegando mais perto daqui (aponta para o polo norte). }\end{array}$ \\
\hline 3 & Professora: E o polo norte, como está? \\
\hline 4 & Aluno 27: Está todo iluminado. \\
\hline
\end{tabular}

Fonte: Construção dos autores.

Nessa ocasião, ressaltamos que o processo de aprendizagem e de desenvolvimento decorre de maneira diferente em cada indivíduo, por conta das distintas ZDPs. Alguns alunos precisam de mais colaboração no desenvolvimento de suas atividades do que outros. Ademais, precisamos considerar que o processo de aprendizagem depende de vários fatores, como interesse pela tarefa e necessidades pessoais, que muitas vezes estão fora do domínio do professor.

Ainda na quarta atividade, destacamos, mais uma vez, a importância da mediação pedagógica no direcionamento da percepção dos alunos sobre o experimento, conforme se evidencia no Episódio 5, adiante. Um dos grupos não conseguia encontrar respostas ao problema, pois mudava o sentido do eixo de inclinação da Terra (bolinha de isopor) durante a simulação do movimento de rotação. Somente após a professora propor um caminho alternativo para solucionar o problema, os alunos chegaram mais perto da resposta. À vista disso, é importante lembrar:

[...] no ensino por investigação, o professor é um orientador da investigação, incentiva a formulação de hipóteses, promove condições para a busca de dados, auxilia as discussões e orienta atividades nas quais os alunos reconhecem as razões de seus procedimentos (TRIVELATO; TONIDANDEL, 2015, p. 110). 
Quadro 5 - Episódio 5 (Atividade 4 da SDAI).

\begin{tabular}{|c|c|}
\hline Turnos & Diálogos estabelecidos \\
\hline 1 & Professora: 0 que vocês descobriram? \\
\hline 2 & $\begin{array}{l}\text { Aluno 11: Prô, a gente conseguiu essa resposta (...) se colocar o globo na posição A fica verão no hemisfério norte e } \\
\text { inverno no hemisfério sul. }\end{array}$ \\
\hline 3 & $\begin{array}{l}\text { Professora: Mas isso explica por que acontece o Sol da meia-noite? Por que será que o polo norte sempre fica de dia } \\
\text { durante o verão? }\end{array}$ \\
\hline 4 & Aluno 4: 0 planeta roda assim, né? \\
\hline 5 & Professora: Que movimento é esse? \\
\hline 6 & Aluno 4: Rotação..., mas eu tô fazendo rotação e não tá ficando dia o tempo inteiro, o polo norte tá ficando escuro. \\
\hline 7 & $\begin{array}{l}\text { Professora: Vocês precisam fazer o movimento de rotação sem mudar o sentido do eixo da Terra, que é o palitinho. Do } \\
\text { jeito que você tava fazendo, o eixo vai ficando diferente. (...) Tenta fazer agora. }\end{array}$ \\
\hline 8 & Aluno 2: Ah, então é assim... \\
\hline
\end{tabular}

Fonte: Construção dos autores.

Após a mediação, os alunos do grupo conseguiram formular com mais clareza suas justificativas, como observamos no Episódio 6.

Quadro 6 - Episódio 6 (Atividade 4 da SDAl).

\begin{tabular}{|c|c|}
\hline Turnos & Diálogos estabelecidos \\
\hline 1 & Professora: $E$ agora? 0 que vocês descobriram? \\
\hline 2 & $\begin{array}{l}\text { Aluno 11: (...) a gente percebeu que quando girava a bolinha assim e o polo norte não ficava o tempo todo iluminado, mas } \\
\text { quando a gente gira assim, do jeito que a senhora falou, fica o tempo todo iluminado. }\end{array}$ \\
\hline 3 & Professora: Isso mesmo. Agora pensem no motivo de isso acontecer. \\
\hline 4 & $\begin{array}{l}\text { Aluno 11: A Terra vai girando e sempre vai pegando luz no polo norte, por isso fica dia o tempo todo no verão. (...) e quando } \\
\text { muda para as outras posições (da órbita) não fica Sol o dia todo no polo norte. }\end{array}$ \\
\hline 5 & $\begin{array}{l}\text { Professora: Isso mesmo, conforme a Terra vai fazendo o movimento de translação, o Sol da meia-noite vai deixando de } \\
\text { acontecer, dai a gente vai ver esse fenômeno acontecendo no polo sul quando for inverno no polo norte. E vocês acham } \\
\text { que o eixo da Terra tem alguma coisa a ver com isso? }\end{array}$ \\
\hline 6 & Aluno 4: A Terra é inclinada, né? Igual nas estações do ano (experiência). \\
\hline 7 & Professora: Sim... 0 que aconteceria se não houvesse a inclinação? \\
\hline 8 & Aluno 4: Não teria estações, né? \\
\hline 9 & $\begin{array}{l}\text { Professora: E o Sol da meia-noite? (professora altera o eixo de inclinação do globo, deixando-o reto e simula o movimento } \\
\text { de rotação). }\end{array}$ \\
\hline 10 & Vários alunos: (...) também não. \\
\hline
\end{tabular}

Fonte: Construção dos autores.

Outra questão, é o nível de dificuldade da atividade proposta. Apesar de a maioria da turma se engajar na busca de uma resposta para o problema, notamos que um grupo de alunos, em especial, não estava se dedicando às atividades. Conversamos com o grupo e percebemos que os estudantes não haviam compreendido alguns conhecimentos relacionados à experiência. Como 0 nível de dificuldade da atividade estava acima de suas possibilidades, eles se distraíram e deixaram de dar atenção à tarefa proposta. É importante ressaltar que a atenção das crianças é muito pequena. Elas não conseguem se concentrar por muito tempo nas tarefas e sua atenção está fortemente ligada aos 
seus interesses pessoais e a sua emoção, conforme explica Rubinstein (1978). Diante de atividades muito além de suas ZDPs, os alunos não conseguem estabelecer conexões entre os conhecimentos.

Para que os alunos conseguissem acompanhar o restante da turma, a professora os incentivou a expressar o que sabiam sobre o tema, realizando correções sempre que necessário. Em seguida, realizou 0 experimento junto com os estudantes, direcionando-os aos elementos mais importantes para resolver a tarefa, como se constata no episódio a seguir.

Quadro 7 - Episódio 7 (Atividade 4 da SDAI).

\begin{tabular}{|c|l|}
\hline Turnos & \multicolumn{1}{c|}{ Diálogos estabelecidos } \\
\hline 1 & $\begin{array}{l}\text { Professora: Que estação do ano é no hemisfério norte? (a pedido da professora, aluno do grupo coloca o globo na posi- } \\
\text { ção A, que corresponde ao verão no hemisfério norte). }\end{array}$ \\
\hline 2 & Todos do grupo: Verão. \\
\hline 3 & Professora: Agora, façam o movimento de rotação, que é responsável pelo dia e pela noite, e observe o polo norte... \\
\hline 4 & Professora: O que vocês observaram no polo norte? \\
\hline 5 & Aluno 9: Fica luz o tempo inteiro. \\
\hline 6 & Aluno 16: Ah, entendi:...... Mesmo ela dando volta (movimento de rotação), fica pegando luz direto bem aqui (polo norte). \\
\hline 7 & Professora: Agora deixem o planeta reto. \\
\hline 8 & Professora: Tá acontecendo o Sol da meia-noite? \\
\hline 9 & Todos do grupo: Não! \\
\hline 10 & Professora: Por quê? \\
\hline 11 & Aluno 9: Por que o planeta tá reto. \\
\hline
\end{tabular}

Fonte: Construção dos autores.

Considerando a situação evidenciada, enfatizamos a importância de identificar as possíveis ZDPs para propor atividades que estejam ao encalce das possibilidades dos alunos.

Na última atividade, chamamos a atenção da turma e solicitamos aos grupos uma exposição oral das respostas encontradas. Como houve poucas manifestações, sugerimos a cada grupo 0 registro, em uma folha de papel, da resposta encontrada para o problema.

Quadro 8 - Respostas dadas ao problema na Atividade 5 da SDAI.

\begin{tabular}{|l|l|}
\hline GRUP0 1 & Porque como a Terra fica inclinada o Sol pega em todo o polo norte então assim os raios solares não deixa ficar de noite. \\
\hline GRUP0 2 & $\begin{array}{l}\text { Se colocar o globo na posição A, no hemisfério norte fica verão e no hemisfério sul fica inverno. Por causa da translação. } \\
\text { Porque no movimento de rotação a tampinha não pode ser girada é o globo que gira e porque se o planeta ficasse reto não } \\
\text { teria as estações do ano e o Sol da meia noite. }\end{array}$ \\
\hline GRUP0 3 & Porque o Sol pega mais no "paulo" norte deves que o "paulo" sul. Por isso pega mais no "paulo" norte. \\
\hline GRUP0 4 & O Sol fica perto do polo norte e o sol bate o polo norte. \\
\hline GRUP0 5 & Não responderam. \\
\hline GRUP0 6 & $\begin{array}{l}\text { O Sol da meia noite acontece na estação verão no hemisfério norte. Por que? R: porque o Sol concentra mais no hemisfério } \\
\text { norte do que no hemisfério sul por isso fica 24h o dia todo iluminado pela luz do Sol. Por que acontece o sol da meia noite? } \\
\text { R: porque no verão o sol só bate no hemisfério norte! A inclinação da Terra tem a ver que faz o sol pegar mais no hemisfério } \\
\text { norte porque a terra fica inclinada é isso que faz o sol da meia noite. }\end{array}$ \\
\hline
\end{tabular}

Fonte: Construção dos autores. 
Em análise às conclusões dos alunos (Quadro 8), verificamos que alguns grupos conseguiram chegar a justificativas que se aproximam de ideias cientificamente corretas, como se constata nas respostas dos grupos 1, 2 e 6, o que é um fato interessante, tendo em vista as dificuldades inerentes à temática investigada. Nessas respostas, evidencia-se indícios de falas da professora, caracterizando o processo de imitação, que consiste em tentativas de imitar a análise intelectual do professor.

Para Vigotski (2007), a imitação não é uma mera repetição de discurso, pois, mesmo que os alunos não compreendam completamente o que expressam, só é possível imitar aquilo que se encontra na zona de potencialidades intelectuais. Dessa maneira, entendemos que a imitação do discurso da professora é uma forma de colaboração e permitiu que os alunos chegassem a conclusões que não chegariam sozinhos.

No entanto, outros grupos permaneceram com concepções alternativas (grupos 3 e 4, respectivamente) ou não responderam (grupo 5). Nessa ocasião, entendemos que o processo de aprendizagem nem sempre segue os caminhos desejados e, mesmo que o professor se empenhe, os indícios de desenvolvimento muitas vezes não acompanham 0 curso de aprendizagem e 0 planejamento pedagógico. Como o processo de elaboração dos conceitos da SDAI está em fases iniciais, somente em momentos posteriores, após ampliação do sistema conceitual, os conhecimentos apreendidos agora poderão fazer diferença significativa.

Devemos considerar, ainda, as dificuldades típicas da aprendizagem de conceitos relacionados à astronomia. A compreensão de fenômenos astronômicos, como movimentos e inclinação da Terra, é muito complicada para as crianças, pois o que o professor ensina contraria os seus sentidos, que mostram um planeta imóvel (PASCHINI NETO; TOMMASIELLO, 2017). Abstrair as sensações (sentidos) é uma tarefa difícil para as crianças, porque o pensamento e as percepções infantis ainda estão diretamente ligados ao mundo concreto. Segundo Vygotsky e Luria (1996, p. 202), é muito difícil para a criança se desligar do objeto que está sendo percebido e extrair dele "um signo correspondente para toda a série de objetos".

Tendo em conta que a construção de conceitos de astronomia continuará nos anos escolares posteriores, julgamos que os conhecimentos propiciados na SDAI contribuíram para a ampliação da generalização de conceitos científicos, atenuando algumas concepções alternativas. As atividades fundamentadas no Ensino por Investigação também possibilitaram momentos em que os estudantes colocaram em prática conhecimentos já estabelecidos para a apreensão de novos, estimulando 0 desenvolvimento de habilidades cognitivas.

\section{CONSIDERAÇÕES FINAIS}

Na SDAl, os estudantes tiveram oportunidades de mobilizar conhecimentos relacionados à astronomia. Apesar de alguns alunos ainda apresentarem concepções alternativas, verificamos indícios de aprendizagem nas tentativas de resolução da situação problema, manifestados pelo emprego de concepções sobre os movimentos de rotação e translação, esfericidade e inclinação do planeta Terra.

0 fato de os estudantes terem voz para expressar concepções sobre o que aprenderam foi importante para a mediação das atividades e identificação dos indícios de aprendizagem. Mesmo que as palavras dos alunos não fossem ditas da forma que se esperava, entendemos que quando uma criança utiliza um conceito, ela está organizando seu pensamento, mobilizando funções cognitivas e criando sistemas de generalizações em volta do conceito, que se amplia conforme a criança aprende na escola. 
Além disso, tendo em conta a complexidade do processo de ensino e aprendizagem de astronomia, entendemos que os conceitos desse tema não são desenvolvidos de forma imediata, assim como a alfabetização científica, que deve ser almejada desde os anos iniciais. Dessa forma, a SDAI deu início ao processo de elaboração de alguns conceitos de astronomia e de habilidades da alfabetização científica, construindo bases para aprendizagens futuras.

De modo geral, as atividades fundamentadas no Ensino por Investigação permitiram que os alunos se vissem envolvidos em uma investigação que exigia alto nível de participação e protagonismo. Consideramos que essa abordagem possibilita a construção de uma imagem mais complexa da Ciência, além de contextualizações com a realidade social e científica, tão importantes na atualidade, onde se tem colocado em dúvida a produção científica que explica a ocorrência dos fenômenos da natureza e da vida.

\section{REFERÊNCIAS}

ANDRÉ, M. E. D. A. Texto, contexto e significados: algumas questões na análise de dados qualitativos. Cadernos de Pesquisa, São Paulo, n. 45, p. 66-71, 1983. Disponível em: https://bit.ly/3Elklx8. Acesso em: 18 maio 2019.

BARTELMEBS, R. C.; MORAES, R. Astronomia nos anos iniciais: possibilidades e reflexões. Revista Espaço Pedagógico, Passo Fundo, v. 19, n. 2, p. 341-352, jul./dez. 2012. Disponível em: https://bit.ly/3zFugVX. Acesso em: 20 ago. 2020.

CACHAPUZ, A.; GIL-PEREZ, D.; CARVALHO, A. M. P.; PRAIA, J.; VILCHES, A. (Orgs.). A necessária renovação do ensino das ciências. São Paulo: Cortez, 2005.

CARVALHO, A. M. P. 0 ensino de Ciências e a proposição de sequências de ensino investigativas. In: CARVALHO, A. M. P. (Org.). Ensino de Ciências por investigação: condições para implementação em sala de aula. São Paulo: Cengage Learning, 2013. cap. 1, p. 1-20.

CARVALHO, A. M. P. Fundamentos Teóricos e Metodológicos do Ensino por Investigação. Revista Brasileira de Pesquisa em Educação em Ciências, v. 18, n. 03, p. 765-794, dez. 2018. Disponível em: https://bit.ly/3nTIVKJ. Acesso em: 20 nov. 2020.

GIL-PÉREZ, D.; VILCHES, A. Una alfabetización científica para el siglo XXI. Obstáculos y propuestas de actuación. Investigación en la Escuela, Sevilla, v. 4, n. 3, p. 27-37, 2001. Disponível em: https://bit.ly/2XMw2Yf. Acesso em: 20 jan. 2021.

GÓES, M. C. R. A abordagem microgenética na matriz histórico-cultural: Uma perspectiva para 0 estudo da constituição da subjetividade. Cadernos CEDES, Campinas, n. 50, p. 21-29, 2000. Disponível em: https://bit.ly/302gMky. Acesso em: 18 mai. 2019.

LANGHI, R. Astronomia nos anos iniciais do Ensino Fundamental: repensando a formação de professores. 2009. 370 f. Tese (Doutorado em Educação para Ciência) - Faculdade de Ciências, Universidade Estadual Paulista, Bauru, SP, 2009. Disponível em: https://bit.ly/3CyNz4Z. Acesso em: 20 nov. 2020.

LANGHI, R. Educação em Astronomia: da revisão bibliográfica sobre concepções alternativas à necessidade de uma ação nacional. Caderno Brasileiro de Ensino de Física, v. 28, n. 2, p. 373-399, ago. 2011. Disponível em: https://bit.ly/ 3tX3Sp4. Acesso em: 22 nov. 2020. 
LANGHI, R. Ideias de senso comum em Astronomia. In: Observatórios Virtuais. São Paulo: IAG/USP, v. CDROM, p. 1-9, 2004.

LANGHI, R.; NARDI, R. Ensino de Astronomia: erros conceituais mais comuns presentes em livros didáticos de ciências. Caderno Brasileiro de Ensino de Física, v. 24, n.1, p. 87-111, abr. 2007. Disponível em: https://bit.ly/3tZSEQz. Acesso em 22 nov. 2020.

PASCHINI NETO, M.; TOMMASIELLO, M. G. C. A rotação e a Translação da Terra: um estudo sobre o que se ensina e o que se vê. Comunicações, Piracicaba, v. 24, n. 1 p. 113-124, jan./abr. 2017. Disponível em: https://bit.ly/3ECJTkp. Acesso em: 22 nov. 2020.

SASSERON, L. H. Alfabetização científica, ensino por investigação e argumentação: relações entre ciências da natureza e escola. Revista Ensaio, Belo Horizonte, v. 17, n. especial, p. 49-67, nov. 2015. Disponível em: https://bit.ly/ 2VZ96UK. Acesso em: 18 jan. 2018.

SASSERON, L. H. Ensino de Ciências por Investigação e o Desenvolvimento de Práticas: Uma Mirada para a Base Nacional Comum Curricular. Revista Brasileira de Pesquisa em Educação em Ciências, v. 18, n. 3, p. 1061-1085, dez. 2018. Disponível em: https://bit.ly/3ILjEQd. Acesso em: 29 mar. 2021.

SETÚVAL, F. A. R.; BEJERANO, N. R. R. Os modelos didáticos com conteúdos de Genética e a sua importância na formação inicial de professores para o ensino de ciências e biologia. In: Encontro Nacional de Pesquisa em Educação em Ciências, 7., 2009, Florianópolis, SC. Atas [...]. Florianópolis: ABRAPEC, 2009, p. 1-12. Disponível em: https://bit.ly/ 3hVOAOS. Acesso em: 15 ago. 2021.

RUBINSTEIN, S. L. Princípios de Psicologia General. México: Grijalbo, 1978.

TRIVELATO, S. L. F.; TONIDANDEL, S. M. R. Ensino por investigação: eixos organizadores para sequências de ensino de biologia. Revista Ensaio, Belo Horizonte, v.17, n. especial, p. 97-114, nov. 2015. Disponível em: https://bit.ly/3hVOCUz. Acesso em: 18 jan. 2018.

VIGOTSKI, L. S. A Formação Social da Mente. 7 ed. São Paulo: Martins Fontes, 2007.

VIGOTSKI, L. S. A Construção do Pensamento e da Linguagem. 2. ed. São Paulo: WMF Martins Fontes, 2009.

VINHOLI JÚNIOR, A. J.; PRINCIVAL, G. C. Modelos Didáticos e Mapas Conceituais: Biologia Celular e as interfaces com a informática em cursos técnicos do IFMS. HOLOS, Natal, v. 2, ano 30, p. 110-122, 2014. Disponível em: https://bit. ly/3hUxKh5. Acesso em: 15 ago. 2021.

VYGOTSKY, L. S.; LURIA, A. R. Estudos sobre a história do comportamento: símios, homem primitivo e criança. Porto Alegre: Artes Médicas, 1996.

ZABALA, A. A prática educativa: como ensinar. Porto Alegre: Artmed, 1998.

ZÔMPERO, A. F.; GONÇALVES, C. E. S.; LABURÚ, C. E. Atividades de investigação na disciplina de Ciências e desenvolvimento de habilidades cognitivas relacionadas a funções executivas. Ciência e Educação, Bauru, v. 23, n. 2, p. 419-436, 2017. Disponível em: https://bit.ly/2W0194h. Acesso em: 18 jan. 2018. 
ZÔMPERO, A. F.; LABURÚ, C. E. Atividades investigativas no ensino de ciências: aspectos históricos e diferentes abordagens. Revista Ensaio, Belo Horizonte, v. 13, n. 03, p. 67-80, set./dez. 2011. Disponível em: https://bit.ly/39r8Dhi. Acesso em: 18 jan. 2018.

RECEBIDO EM: 04 maio 2021

CONCLUÍDO EM: 26 maio 2021 
